\title{
O trabalho dos laboratórios, a indústria do alcatrão mineral e a hodierna concepção de atividade científica
}

\author{
Renan Springer de Freitas*
}

Resumo: O vínculo duradouro existente entre a indústria e a ciência tal como hoje o conhecemos só começou a se estabelecer em meados do século XIX. Neste artigo, argumento que o estabelecimento deste vínculo se deu por meio de uma alteração radical do próprio modo de conceber a atividade científica. Trata-se, então, de mostrar qual foi a nova concepção de atividade científica surgida em meados do século XIX e como ela veio a se estabelecer. Sugiro que a resposta está no entrelaçamento de duas atividades inexistentes até o século XIX: a do trabalho sistemático dos laboratórios, que só ganhou dimensão institucional na década de 1830, e a da exploração do alcatrão mineral para fins industriais, que só teve início em 1856.

Palavras chave: Revolução Industrial. Cultura científica inglesa. Justus von Liebig. Indústria do alcatrão mineral. Desenvolvimento industrial no século XIX.

\section{The work of laboratories, the coal tar industry, and the current conception of scientific activity}

Abstract: The enduring link which exists between industry and science as we know it today only began to be established in the middle of the 19th century. In this article I argue that the establishment of this link occurred by means of a radical change in the very way of conceiving scientific activity. Thus, I show what was the new conception of scientific activity that appeared in the middle of the 19th century and ask how it came to be established. I suggest that the answer lies in the interweaving of two activities that did not exist until the 19th century: the systematic work of the laboratories, which only gained an institutional dimension in the 1830s, and the exploitation of coal tar for industrial goals, which only started in 1856.

Keywords: Industrial Revolution. English scientific culture. Justus von Liebig. Coal tar industry. Industrial development in 19th century.
Recebido: 26.01.19

Aprovado: 17.02 .20
* Renan Springer de Freitas é professor titular do Departamento de Sociologia da Universidade Federal de Minas Gerais (UFMG), Belo Horizonte, Minas Gerais, Brasil, membro do Conselho Editorial do periódico Philosophy of the Social Sciences. Orcid: 0000-00016109-6841. $<$ renanweil@gmail. com>. 
“A conexão da indústria com a ciência moderna, especialmente o trabalho sistemático dos laboratórios, [...] permitiu que a indústria se tornasse o que é hoje".

Max Weber

1. Veja-se,

especialmente, o trabalho de Joel Mokyr (2007), em quem me apoiei para descrever esse estranho tempo da indústria sem ciência.

2. Para John D. Bernal (1953: 145), "a indústria da engenharia [...] permaneceu em larga medida fora dos principais movimentos científicos do século XIX porque, em grande parte, os problemas levantados pela engenharia mecânica, quando eram de natureza matemática, [...], podiam ser resolvidos pela geometria e pelo cálculo simples já existentes no século XVIII, e quando se relacionavam com a física, [...] a solução estava além das possibilidades da física do século XIX."

3. Esta é, por exemplo, a visão de Albert Musson e Eric Robinson (1969).
$\Lambda$ atividade industrial característica do nosso tempo é tão nitidamente vinculada à atividade científica que soa até contraintuitivo imaginar um tempo em que esse vínculo pudesse não existir. Mas esse tempo existiu. Foi um tempo em que a fabricação de máquinas era desvinculada da ciência que se dedica ao estudo do funcionamento das máquinas (a mecânica), a fabricação de metais desvinculada da ciência que se dedica ao estudo do processo de fabricação de metais (a metalurgia), a fabricação de produtos sintéticos desvinculada da ciência que se dedica ao estudo da composição química dos produtos sintéticos (a química) e a extração de minério desvinculada da mineralogia, o ramo da ciência ( a geologia) que se dedica ao estudo dos componentes do minério. Não se sabe ao certo até quando esse tempo se estendeu. Para alguns estudiosos, teria sido até mais ou menos o ano de $1750^{1}$.Depois disso, dizem, as repercussões tecnológicas da revolução científica ocorrida no século anterior começaram a se fazer sentir. 0 ponto alto desse processo teria sido a fabricação do revolucionário motor a vapor, na década de 1770, com seu conhecido impacto sobre o crescimento da produção industrial inglesa (Jacob, 1997). Para outros estudiosos, entretanto, os inventos revolucionários da engenharia mecânica do século XVIII, incluindo o mais espetacular de todos, o aludido motor a vapor de James Watt, nada devem à mecânica newtoniana ou a qualquer outra contribuição científica digna de nota (Hall, 1974). O legendário historiador da ciência John D. Bernal vai ainda mais longe, ao sugerir que nem mesmo no século XIX a mecânica teve um impacto importante sobre a indústria da engenharia mecânica - ou de fabricação de máquinas²

No presente trabalho posso me dar ao luxo de ignorar essa polêmica porque, ainda que se conceda que o impulso para o desenvolvimento industrial inglês, a partir de meados do século XVIII, tenha sido dado pela entrada em cena das contribuições científicas espetaculares trazidas no século anterior, quer pela mecânica de Newton, quer, também, como sustentam alguns historiadores da ciência, pela química de Boyle; ; ainda que se conceda, em termos mais gerais, que já no século XVIII a produção industrial começou a ser impulsionada pelo conhecimento científico e, na mesma medida, a oferecer novas condições para o avanço desse conhecimento, permanece a questão de saber como e por que se estabeleceu, somente no século XIX, o vínculo duradouro entre a ciência e a indústria tal como hoje o conhecemos. 
Até onde sei, essa questão foi formulada pela primeira vez em 1953, pelo já citado John D. Bernal, de quem, a propósito, tomei de empréstimo a expressão "vínculo duradouro" (Bernal, 1953: 138). Entretanto, Bernal não esclarece devidamente a natureza do vínculo cuja origem ele próprio se dispôs a estudar. Ouso tentar fazê-lo agora, nos seguintes termos: afirmar a existência de um "vínculo" entre as atividades industrial e científica não se resume a afirmar que em algum momento o conhecimento científico, até então irrelevante, ou de importância secundária, para a produção industrial, passou a ser importante, ou, mesmo, fundamental; não se resume a afirmar, por exemplo, que em algum momento o conhecimento de metalurgia, mineralogia e química orgânica passou a ser de fundamental importância para a fabricação de, respectivamente, ferro, minério e produtos sintéticos (como adubos e corantes artificiais). Se algum vínculo veio a se estabelecer entre essas atividades e a atividade científica, não é meramente no sentido de que as primeiras foram impulsionadas, ou mesmo viabilizadas, pelo conhecimento produzido por esta última e, na mesma medida, ofereceram novas condições para que este conhecimento pudesse também prosperar. Muito mais que meramente fazer uso do conhecimento científico e, em contrapartida, favorecer o seu avanço, houve um momento a partir do qual a atividade industrial passou a depender de algo inteiramente novo, a saber, a formação de cientistas dedicados à atividade rotineira de pesquisa; mais precisamente, de químicos profissionais, devidamente especializados em metalurgia (para a fabricação de ferro), mineralogia (para a extração mineral) e química orgânica (para a produção de adubos e corantes sintéticos). Ingressamos, dessa forma, em uma era em que a atividade industrial, muito mais que meramente impulsionada pelo avanço do conhecimento científico, como teria ocorrido - ou talvez nem o tenha, se Rupert Hall (1974) e Bernal (1953) tiverem razão - a partir da segunda metade do século XVIII, veio de fato a se vincular à atividade científica e dela se tornar irreversivelmente dependente. Como foi que esse vínculo, agora, verdadeiramente visceral, veio a se estabelecer?

Neste trabalho me proponho a oferecer uma resposta. Esse desafio não é fácil porque, como já foi insinuado, há mais de 60 anos ninguém menos que Bernal se propôs a responder "como e por quê", no século XIX, "se forjou" o "vínculo duradouro entre a ciência e a indústria" (Bernal, 1953: 138). Passado todo esse tempo, o que pode haver para ser acrescentado à contribuição seminal e sem paralelo de Bernal? Paradoxalmente, a resposta está em uma afirmação incidental, feita mais de três décadas antes da obra de Bernal vir a público, por alguém que sequer historiador da ciência era - e, muito menos, professor de física, como o era Bernal. Seu nome: Max Weber. O leitor já foi apresentado a essa afirmação: são as linhas que servem de epígrafe a este artigo. Talvez não seja ocioso mencionar que no 
texto de Weber essas linhas arrematam uma breve discussão a respeito do desenvolvimento industrial inglês no século XIX.

4. Como é sabido, o livro General economic history foi publicado postumamente, a partir de anotações dos alunos de Weber.

5. Os trabalhos paradigmáticos que apontam nessa direção são: Margaret Jacob (1997), Margaret Jacob e Larry Stuart (2004) e toda uma vasta obra de Joel Mokyr, da qual destaco Mokyr (2005) e a já citada conferência de 2007. Cabe também mencionar Neil McKendrix (1973) Larry Stewart (1986).
Inicio a discussão retomando essas linhas, agora, sem omissões:

\begin{abstract}
A conexão da indústria com a ciência moderna,especialmente o trabalho sistemático dos laboratórios, começando com Justus von Liebig, permitiu que a indústria se tornasse o que é hoje e, então, conduziu o capitalismo ao seu pleno desenvolvimento (Weber ${ }^{4}$, 2003: 306).
\end{abstract}

A simples menção a Justus von Liebig (1803-1873), químico alemão radicado em uma cidade alemã chamada Giessen, e ao seu "trabalho sistemático de laboratório", realizado na universidade dessa cidade, desafia seriamente a visão de toda uma literatura recente, produzida pelos mais notáveis historiadores da ciência e da economia, que, ao seu próprio modo, também se ocupam da "conexão da indústria com a ciência moderna". De acordo com esses historiadores, esta conexão começou a se estabelecer em meados do século XVIII, nos albores da Revolução Industrial inglesa, devido ao fato de a Inglaterra ter sido o único país do mundo a desenvolver, já no remoto século XVII, uma cultura científica que efetivamente favorecia a produção industrial ${ }^{5}$.

Com efeito, desde o final do século XVII teve início na Inglaterra, e somente na Inglaterra, a publicação de edições sucessivas de livros-textos de física newtoniana. Pouco depois, o ensino prático de física foi também introduzido, embora não como disciplina obrigatória da grade curricular dos cursos universitário ou de nível médio. Ele se dava através de demonstrações experimentais das leis da física, realizadas em eventos regularmente promovidos para essa finalidade. Pelo que me foi dado a entender, o que ocorria nesses eventos era algo parecido com o que em nossos dias ocorre nas boas "aulas práticas" de física oferecidas nos cursos técnicos de nível médio, ou, mesmo, de engenharia. Mas comparecia quem quisesse. Para coroar tudo isso, havia palestras periódicas proferidas pelos maiores nomes da ciência da época - até mesmo Dalton deu sua contribuição, proferindo uma palestra em Manchester, já no tardio ano de 1815 (Jacob, 1997). Em uma sociedade permeada por uma cultura científica de tal natureza, dizem os referidos historiadores, na qual um jovem que se dedica à fabricação de máquinas, tecidos, ou qualquer outro produto industrial pode estar diretamente em contato com tudo o que em sua época há de mais relevante em matéria de conhecimento científico, nada haveria de sur- 
preendente no surgimento dos nomes legendários - a começar pelo de James Watt - usualmente associados aos inventos espetaculares que impulsionaram a produção industrial. Nessa perspectiva, os fabricantes ingleses, em razão de terem sido expostos, desde a mais tenra idade, a uma cultura científica peculiarmente inglesa, foram capazes de mobilizar o conhecimento científico para fins industriais de uma forma que só poderia ser vista na própria Inglaterra. A organização, em 1851, da primeira Grande Exposição dos Trabalhos de Indústria de Todas as Nações (Great Exhibition of the Works of Industry of all Nations), a mais espetacular exposição de produtos industriais de que se tem notícia, realizada no Palácio de Cristal, em Londres, teria sido o inequívoco indicador, ainda que um pouco tardio, de toda essa excepcional exuberância da cultura científica inglesa.

Há de se conceder aos historiadores da economia e da ciência que uma cultura científica peculiarmente inglesa se formou já no remoto século XVII, na esteira da física newtoniana, tendo desde então prosperado a ponto de poder exibir, em pleno ano de 1851, sua incomparável exuberância. Weber nos faz ver, entretanto, que disto não resulta que essa cultura tenha de alguma forma conectado a indústria à ciência moderna. A lição imediata a ser extraída de sua menção incidental ao "trabalho sistemático dos laboratórios" é a de que a cultura científica inglesa, mesmo com toda sua exuberância, não tem relação com o vínculo duradouro que veio a se estabelecer, na própria Inglaterra, e por volta do mesmo glorioso ano de 1851, entre as atividades científica e industrial. Conforme vimos, essa cultura se formou a partir da ampla difusão de livros-textos, demonstrações experimentais e aulas magnas. Ocorre, entretanto, que nada disso conecta a ciência à indústria, embora possa inegavelmente conduzir à produção de um conhecimento potencialmente útil para a produção industrial. O conhecimento das leis da termodinâmica, por exemplo, pode ser utilizado para minimizar o dispêndio de energia quando se fabrica um motor a vapor. Mas esse conhecimento está longe de conectar a ciência à indústria porque não torna a produção em escala industrial do motor a vapor dependente da formação sistemática de físicos especializados em termodinâmica, nem, tampouco, impulsiona a pesquisa em termodinâmica. Para que se possa dizer com propriedade que as atividades industrial e científica estão conectadas, é necessário que a produção industrial se torne dependente da formação em massa de cientistas e que o conhecimento produzido por eles impulsione a pesquisa sistemática. Ora, o que viabilizou tanto uma coisa quanto a outra foi exatamente o advento do trabalho sistemático dos laboratórios. Este fez com que tudo mudasse de figura: se antes, o que importava era a formação e o cultivo permanente de talentos supostamente promissores - como um James Watt -, agora, o que importa é algo radicalmente distinto e até então inteiramente desconhecido, a saber, o esforço sistemático no sentido de institucionalizar disciplinas científicas, criar institutos de pesquisa asso- 
6. Refiro-me a Boussingault. Vejase, Juergen Heinrich Maar (2006: 1131).

ciados a universidades, universalizar o acesso às universidades e ao conhecimento por elas gerado e, sobretudo, formar pessoas dispostas a se dedicar em tempo integral ao trabalho árido e miúdo da rotina dos laboratórios. Um esforço dessa natureza, que só teve início no século XIX, conferiu à atividade científica uma feição jamais conhecida até então. Foi somente após assumir essa nova feição, que nada deve à cultura científica inglesa tão bem descrita por historiadores de primeira linha, como Margareth Jacob, que a atividade científica pôde efetivamente se vincular à atividade industrial.

Isso remete às seguintes perguntas: como o referido esforço veio a ser empreendido? Por que, no caso específico da Inglaterra, ele foi por algum tempo bem-sucedido e, depois, deixou de sê-lo? De que modo o trabalho de Liebig, cujo laboratório estava situado em uma cidadezinha alemã que chegou a ser chamada de "insignificante lugarejo de fim de mundo" por um importante químico francês contemporâneo de Liebig que lá esteve ${ }^{6}$, se relaciona com a realização desse esforço? Em termos mais gerais, de que modo o trabalho sistemático dos laboratórios, começando com o de Justus Liebig, conduziu à (hodierna) concepção de atividade científica que, no século XIX, conectou a indústria com a ciência moderna? Penso que sem uma boa resposta para essas perguntas permaneceremos sem saber como foi que se estabeleceu o vínculo duradouro entre a ciência e a indústria, que se tornou tão característico do nosso tempo. Nas seções seguintes ocupo-me delas.

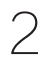

O caso inglês é especialmente talhado para a presente discussão porque a Inglaterra é o único país em que o vínculo entre a ciência e a indústria se fez e, posteriormente, se desfez, com consequências funestas para a sua produção industrial. Dentre essas consequências, destaca-se, conforme veremos, a queda vertiginosa, em termos comparativos, da produção de patentes pela indústria de exploração de alcatrão mineral (coal-tar industry), a mais importante indústria química de então. Vou me deter nessa indústria não somente por sua singular importância, mas por ser um caso paradigmático de indústria que só é viável na medida em que consegue se manter visceralmente vinculada à atividade científica.

O alcatrão mineral é um líquido oleoso, preto, que necessariamente se produz quando se destila a hulha, um tipo especial de carvão mineral, com o objetivo de produzir gás. Há nesse óleo uma enorme variedade de compostos orgânicos, os quais, uma vez retirados do óleo, separados uns dos outros, e submetidos a operações variadas (tais como a oxidação, redução, nitração, sulfonação, diazotização, 
dentre outros), podem ser aproveitados para a fabricação, em escala industrial, de produtos sintéticos os mais diversos. Os primeiros produtos sintéticos fabricados foram os corantes artificiais. Posteriormente a fabricação se estendeu para medicamentos, perfumes, adoçantes, antitoxinas, fertilizantes e até mesmo reveladores fotográficos. A "indústria de exploração do alcatrão mineral" é assim chamada porque se destina a extrair os referidos compostos orgânicos desse óleo, separá-los uns dos outros, purificá-los e submetê-los aos processos para fabricar produtos sintéticos. A primeira indústria dessa natureza estabelecida na Inglaterra - e, evidentemente, no mundo - foi criada em 1856 por um químico chamado William Perkin (1838-1907), a quem oportunamente retorno.

A indústria do alcatrão mineral prosperou na Inglaterra entre 1856 e $1870^{7} . U m$ bom indicador de prosperidade é a quantidade de patentes registradas. Há outros indicadores, aos quais retorno oportunamente, mas por ora é mais conveniente restringir-me às patentes. Consta que nos prósperos tempos iniciais, os químicos que solicitavam registros de patentes de corantes produzidos a partir de compostos orgânicos presentes no alcatrão mineral eram todos ingleses ou franceses ${ }^{8}$. Não se viam nomes alemães. Havia duas exceções, August Wilhelm von Hofmann - um dos heróis da minha história, conforme se verá - e Heinrich Caro, um gigante da química orgânica da época. Essas exceções não eram, entretanto, tão excepcionais assim, uma vez que tanto Hofmann quanto Caro residiam, pelo menos até então, na Inglaterra (Tilde, 1915 [1914]: 316). Von Hofmann, diga-se desde já, tinha chegado à Inglaterra pelas mãos de Liebig. Embora alemão, coube a ele, e não a algum químico inglês, a tarefa de relatar o desempenho da indústria química inglesa no mais importante e espetacular evento industrial da época, a Grande Exposição dos Trabalhos da Indústria de Todas as Nações, não a primeira, a de 1851, jamais igualada em exuberância, mas a terceira, ocorrida em 1862, outra vez em Londres. O relato de Hofmann exalava ufanismo:

\footnotetext{
A esplêndida exibição da indústria química é uma prova de que os ingleses não só têm mantido a sua preeminência dentre os fabricantes de produtos químicos de todo o mundo mas, também, que ultrapassaram sua própria incontroversa superioridade na ocasião correspondente de $1851^{9}$.
}

Esse entusiasmo se baseava, sobretudo, no fato de que, de um total de 762 expositores do ramo da indústria química, 200 representavam o Reino Unido, enquanto a França, a "segunda colocada", teve 115 representantes, e a Alemanha e a Áustria, somadas, atingiram apenas a marca de $136^{10}$. Esse quadro auspicioso da década de 1860 contrasta radicalmente com o que viria a acontecer apenas duas décadas mais tarde, conforme atestam os dados sobre o registro de patentes. Estes são elo-

7. Veja-se Walter M. Gardner (1915: VIII), "Introdução".

8. William A. Tilde, "The supply of chemicals to Britain and her dependences", Journal of the Royal Society of Arts, 27 Nov. 1914 Este trabalho seria reeditado por Gardner (1915: 316).

9. August Wilhelm von Hofmann,

"Report on chemical and pharmaceutical products and processes", p. 3, citado por William Tilde (1914: 316).

10. Idem, ibidem. 
11. Arthur G. Green, "The relative progress of the coaltar colour industry in England and German during the past fifteen years", 1901. Este trabalho seria reeditado por Gardner (1915: 198).

12. A primeira edição desta obra foi publicada em 1953, mesmo ano em que Bernal publicou o artigo aqui anteriormente citado com esse mesmo título. quentes: no período 1886-1890, foram 86 registros da indústria inglesa contra 948 das indústrias alemãs ${ }^{11}$ (Green, 1915: 198)! Por mais que se possa argumentar que as leis de patente inglesas eram mais restritivas, a diferença não abre espaço para qualquer dúvida sobre o declínio inglês. Nem Liebig nem Hofmann viveram para testemunhar esse vertiginoso declínio, mas é no advento do "trabalho sistemático dos laboratórios", tal como realizado por ambos, que reside, conforme veremos, a explicação tanto para a justificada euforia dos tempos iniciais como para a desolação característica dos tempos que se seguiram.

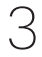

Embora a importância do trabalho de Liebig não tenha escapado a Weber, desconheço menções a esse químico alemão na literatura produzida a respeito da conexão entre as atividades científica e industrial. Bernal é uma exceção. Mas quem lê suas referências, às vezes alentadas, ao trabalho de Liebig, não é levado a pensar que o mesmo possa ter tido a importância que teve para o estabelecimento do "vínculo duradouro" a que o próprio Bernal se referiu. Consideremos, por exemplo, o que Bernal diz em seu livro Science and industry in the Nineteenth Century:

A era da grande pesquisa de laboratório só começou na década de 1860, inspirada em grande medida por Liebig, e se espalhou da Alemanha muito vagarosamente para todo o mundo (Bernal, 2011: $155-156)^{12}$

Em primeiro lugar, Liebig fez muito mais que meramente "inspirar" a "grande pesquisa de laboratório", conforme veremos. Ele, a bem dizer, é um dos protagonistas do processo por meio do qual se estabeleceu a concepção de "pesquisa de laboratório", tal como a entendemos hoje. Em segundo, Bernal pode levar um leitor desavisado a concluir, equivocadamente, que os referidos "laboratórios de pesquisa" pouca ou nenhuma importância tiveram fora da Alemanha antes da década de 1860, não tendo tido, então, qualquer importância para o desenvolvimento industrial inglês da segunda metade do século XIX.

Para afastar esses equívocos é preciso, antes de tudo, mencionar que foi somente na década de 1820 que o ensino de química foi introduzido nas universidades inglesas, cujas grades curriculares eram inspiradas nas grades curriculares das universidades escocesas, e, mesmo assim, para ser ensinada apenas nos cursos de medicina. Havia, então, três categorias de médico: os "físicos" (physicians), os cirurgiões e os "boticários". Aprender química era, então, tão somente o meio de se credenciar para transitar entre essas categorias e se elevar à condição de "clínico geral" 
(Gerrylynn, 1976: 440). Nesse sentido, a química nada mais era que uma disciplina auxiliar na formação do médico. Mas esse quadro viria a mudar radicalmente poucas décadas depois. A química galgou a condição de disciplina científica autônoma e passou a ser aplicada nos ramos mais fundamentais da vida econômica ${ }^{13}$. Já nos anos 1840, ela irrompeu no cenário científico inglês para fazer a diferença. E, antes que o século acabasse, ela se retirou desse cenário, deslocou-se para a Alemanha, para outra vez fazer a diferença: 86 patentes de indústrias químicas inglesas contra 948 alemãs entre 1886 e 1890, conforme vimos.

Concentremo-nos, entretanto, nos promissores momentos iniciais. Nesses, conforme mostrou Joseph S. Fruton (1988), os empreendedores dos diferentes ramos da atividade econômica inglesa perceberam que sem a ajuda da química orgânica não poderiam ir muito longe. Perceberam, por exemplo, que a agricultura depende da química orgânica para o uso racional do solo e de fertilizantes. Da mesma forma, a indústria têxtil não pode prescindir da química orgânica se quiser obter corantes duradouros para os tecidos. Uma nova agricultura e uma nova indústria - a da exploração do alcatrão mineral - já apresentada ao leitor, puderam se desenvolver desde então. Como, entretanto, os empreendedores ingleses puderam perceber que sem a ajuda da química orgânica não seria possível ir muito longe? Como, em primeiro lugar, puderam tomar conhecimento da existência da até então desconhecida "química orgânica"? A resposta está em um nome próprio: Justus Liebig, a quem, aliás, se credita o título de "fundador" da química orgânica. Seu livro de divulgação científica, Familiar letters of chemistry, de 1843, foi publicado em inglês antes de ser publicado em alemão! Ele teve nada menos que 51 edições em inglês (Fruton, 1988: 1)!

Mas antes disto, em 1837, Liebig fez sua primeira de quatro visitas à Inglaterra. Ele foi a convite de um de seus ex-alunos escoceses em Giessen, Thomas Thompson Jr., cujo pai, Thomas Thompson, professor da Universidade de Glasgow, a quem retorno detidamente, foi um dos mais importantes químicos de seu tempo. O convite era para participar do prestigiado Congresso da British Association for the Advancement of Science, ocorrido em setembro daquele ano, em Liverpool. Embora Thomas Thomson, o pai, dirigisse, em Glasgow, o mais conceituado laboratório de química então existente em todo o Reino Unido, não foi em Glasgow que seu filho se fez químico, mas na distante e inexpressiva Giessen! Se, em Glasgow, o grande e destacado centro de então, Thomson Jr. era o filho do grande Thomas Thomson, na pequena Giessen ele era apenas mais um, dentre as dezenas de alunos estrangeiros que acorriam anualmente para aquela cidade. O laboratório de Liebig atraía estudantes dos Estados Unidos e de toda a Europa. A Inglaterra não era exceção - não obstante ser a terra de Newton, Boyle, Dalton, Faraday e, por que não dizer,

13. Bernal (1971: 555), afirmou que a "química foi especialmente a ciência do século XIX". 
do próprio Thomson. Liebig aceitou os sucessivos convites porque vislumbrava a possibilidade de implantar na Inglaterra o ensino teórico e prático de química e a pesquisa sistemática em química orgânica do modo como já se fazia em Giessen. Seu esforço se traduziu, em 1845, na criação do Royal College of Chemistry, uma Instituição pública, embora contasse com a ajuda de recursos advindos da iniciativa privada, destinada exclusivamente ao ensino e à pesquisa de química, cuja direção coube a um jovem ex-aluno que ele próprio escolheu. Refiro-me a August Wilhelm Hofmann (1818-1892), já apresentado ao leitor.

Von Hofmann interessa sobremaneira à presente discussão porque foi, junto com Liebig e Thomson, o maior responsável pelo advento da concepção de atividade científica que veio a se tornar característica do mundo industrializado a partir do século XIX. Vinte e três anos após sua morte, em 1915, o químico Walter M. Gardner, então diretor do Bradford Technical College, uma escola criada em 1882 especialmente para atender às necessidades educacionais das indústrias têxteis de Bradford, reuniu, em um único e alentado documento, os mais importantes discursos e palestras até então proferidas na Inglaterra sobre a fundação, ascensão e declínio da indústria do alcatrão mineral no país (Gardner, 1915). Pois nesse documento, cuja primeira contribuição, de William Perkin, publicada originalmente em 1856, ano da fundação, pelo próprio Perkin, da primeira indústria do ramo, nenhum químico ou industrial foi tão mencionado quanto Hofmann. Há 251 referências ao seu nome. Nem mesmo Perkin, que ganhou enorme notoriedade em razão de ter fabricado com sucesso o primeiro corante sintético, a "malva de Perkin", a partir do alcatrão mineral, é tão mencionado. Veremos oportunamente que há muito boas razões para que Hofmann, que não era inglês nem industrial, mas alemão e químico, seja mais lembrado do que qualquer inglês e industrial nos pronunciamentos mais importantes já realizados na Inglaterra da segunda metade do século XIX, e primeira década do século XX, sobre a trajetória e as perspectivas da indústria química desse país.

Na seção 1 mencionei que no século XIX se estabeleceu a hodierna concepção de que a atividade científica não merece esse nome se não envolver esforços sistemáticos no sentido de institucionalizar disciplinas científicas, criar institutos de pesquisa associados a universidades, universalizar o acesso às universidades e ao conhecimento por elas gerado e, sobretudo, formar pessoas dispostas a se dedicar em tempo integral ao trabalho árido e miúdo das rotinas dos laboratórios. Cumpre-me, a partir de agora, a tarefa de mostrar o modo como se deu a emergência dessa concepção na sociedade inglesa, podendo desde já adiantar que ela está atrelada ao processo por meio do qual a química deixou de ser uma mera disciplina auxiliar da grade curricular dos cursos de medicina para se tornar uma disciplina autôno- 
ma e de reconhecida centralidade para as atividades industrial e agrícola. Adianto também que, no que se refere especificamente à concepção, hoje trivial, mas nada trivial na Inglaterra da primeira metade do século XIX, de que a atividade científica pressupõe a formação sistemática de cientistas, esta se introduziu na Inglaterra graças, fundamentalmente, ao trabalho de Hofmann como diretor do anteriormente citado Royal College of Chemistry.

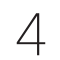

Devo iniciar mencionando que a institucionalização da química como disciplina científica na Inglaterra está indissociavelmente ligada à universalização do ensino e do acesso às universidades nesse país, e essa universalização tem pouco ou nada a ver com os ingleses e, menos ainda, com a já citada "cultura científica inglesa". Ela deve ser creditada, fundamentalmente, a reformadores educacionais escoceses com grande experiência de ensino extramuros em seu país natal. Dentre esses escoceses há um nome legendário: Henry Brougham, advogado, membro do parlamento britânico, figura chave na fundação, em 1825, da primeira universidade inglesa projetada para receber estudantes de qualquer estrato social e qualquer religião, ou mesmo sem religião. Refiro-me à University of London, um ano mais tarde rebatizada como University College London (UCL). Foi sob a inequívoca liderança de Brougham que os reformadores educacionais escoceses introduziram, a duras penas, na vida social inglesa, a ideia, hoje trivial, mas nada trivial na época, de que o acesso ao conhecimento científico e à universidade deve ser universalizado ${ }^{14}$.

A University College London interessa à presente discussão não só por ter sido a primeira experiência institucional bem sucedida de universalização do acesso ao ensino universitário na Inglaterra, mas, sobretudo, por ter desempenhado um papel importante no processo que conduziu à institucionalização da química como disciplina científica: ela foi a primeira instituição de ensino inglesa a introduzir a aula prática de química na grade curricular dos cursos de medicina. De forma nada surpreendente, o primeiro professor de química contratado - em 1828 - por essa universidade, Edward Turner, não era inglês, mas um escocês que dava aulas práticas de química extramuros em Edimburgo. Turner morreu precocemente e foi substituído, em 1837, por Thomas Graham, um professor que, outra vez, nada surpreendentemente, "aprendeu química no contexto da tradição prática escocesa" (Roberts, 1976: 443).O nome de Graham remete diretamente ao de Liebig. Conforme já vimos, em 1837 Liebig visitou o Reino Unido e, após retornar a Giessen, seu "lugarejo de fim de mundo", escreveu o seguinte a Berzelius (1779-1848), químico sueco cuja reputação quase rivalizava com a de Lavoisier:

14. Tanto o projeto de universalização do acesso à universidade, como o próprio Brougham, em pessoa, enfrentaram impiedosa resistência dos Tories, da Igreja anglicana e, mesmo, de segmentos intelectualizados da Inglaterra. A University College London teve de vencer essa resistência para permanecer em funcionamento. Os detalhes dessa resistência estão muito bem registrados no excelente livro de Rosemary Ashton (2012). 
15. J. Carrière (Org.), Berzelius und Liebig: Ihre Briefe Von 1831-1845 (Munich e Leipzig), citado por Joseph S. Fruton, "The Liebig Research Group: A Reappraisal", Proceedings of the American Philosophical Society, v. 132 , n. 1 , p. 32 1988
Passei alguns meses na Inglaterra, vi muita coisa horrível e aprendi pouco. A Inglaterra não é uma terra de ciência, há apenas um diletantismo amplamente praticado [...]. Do ponto de vista científico, Graham é a exceção mais notável [...] (destaque acrescentado) $)^{15}$.

Embora não haja, na citação acima, nem no artigo do qual a retirei, maiores esclarecimentos sobre os atributos que, "do ponto de vista científico", faziam de Graham (1805-1869) a "exceção mais notável", esse esclarecimento é imprescindível; ele é a pista para identificar a concepção de atividade científica que Liebig pretendia introduzir, e conseguiu fazê-lo via Hofmann, no cenário científico inglês. Um discurso proferido em homenagem póstuma a Hofmann, em 1893, quase 70 anos após o encontro entre Liebig e Graham, por Lyon Playfair (1818-1898), destacado químico a quem já havia sido confiada, em 1885, a presidência da British Association for the Advancement of Science, trouxe esse esclarecimento. Reproduzo, abaixo, a passagem esclarecedora:

A Inglaterra nunca foi deficiente em grandes pesquisadores na área de química, mas não havia escolas práticas para treiná-los. Na verdade, podemos reivindicar com perfeita justiça que um grande número de descobertas que fizeram da química uma ciência tiveram origem neste país. O século passado foi especialmente fecundo. A descoberta fundamental do oxigênio e outras descobertas pneumáticas de Priestley; os estudos sobre a composição do ar e sobre o calor latente de [Joseph] Black; a descoberta simultânea da composição da água por Cavendish e Wedgwood; o trabalho de Dalton, que trouxe lei e ordem para as nossas caóticas ideias sobre combinação química; todas essas descobertas radicais formam o próprio fundamento da química. No século presente devo também começar por Dalton [...]. Dalton, Davy, Faraday e Graham realmente se destacam como um farol em nosso próprio século. Davy e Faraday eram pesquisadores brilhantes; eles tinham um incomparável encanto e uma eloquência singular quando davam palestras. A eles devemos a grande popularidade da química em nosso país. Mas nenhum desses químicos, exceto Graham, pensou em abrir seus laboratórios para o treinamento dos estudantes nos métodos de pesquisa. [...] Fui estudante em seu laboratório em 1835 e 1836, e o segui em Londres como seu assistente particular de laboratório na University College [London]. O exemplo de Graham se espalhou e muitas faculdades, mesmo as universidades, pouco a pouco se adaptaram à visão de que os laboratórios eram necessários para ensinar e treinar os químicos do futuro (Playfair, 1896: 576, destaque acrescentado).

Eis, em síntese, o que fazia de Graham a "exceção mais notável" no cenário científico inglês do século XIX: o empenho em "abrir os laboratórios" para "ensinar e 
treinar os químicos do futuro". Hoje soa trivial, mas definitivamente não o era na Inglaterra da década de 1830. Para além de Graham, Liebig admirava o trabalho de seu mentor científico: Thomas Thomson (1773-1852), aquele cujo filho foi estudar em Giessen e, posteriormente, fez o convite que resultou na primeira visita de Liebig à Inglaterra. Thomson, diga-se sem rodeios, foi a figura que inaugurou a "tradição prática escocesa" em que Graham se formou. Na verdade, tudo o que foi dito anteriormente sobre Graham veio de Thomson, conforme se pode depreender do mais que esclarecedor excerto abaixo, do historiador da ciência John Bowes Morrell:

Em contraste com seus eminentes químicos contemporâneos britânicos como Humphry Davy, John Dalton e William Hyde Wollaston, Thomson ocupou um posto docente universitário a partir do qual tentou criar um centro de pesquisa com base em seu laboratório de ensino. Embora Davy e Dalton tenham formado alunos que vieram a se destacar, eles não compartilhavam uma das mais acalentadas ambições de Thomson, a de "elevar o laboratório a uma escala que pudesse viabilizar o estabelecimento de uma verdadeira escola de química em Glasgow e a formação de uma nova geração de químicos práticos ${ }^{16}$." Em contraste, também, com seus colegas britânicos ainda ativos na década de 1820 , ele queria não só desenvolver o ensino prático de sua especialidade [a química analítica], no laboratório que abriu para seus estudantes em 1818, como também criar na Universidade de Glasgow, onde lecionava, um instituto de pesquisa funcionando sob sua direção. Esse tipo de ambição era muito incomum naquele tempo. Ela contrastava fortemente com, por exemplo, a indiferença em relação ao ensino prático de química mostrado por Thomas Charles Hope, o sucessor de [Joseph] Black na cátedra de química na Universidade de Edimburgo (Morrell, 1972: 2-3, destaque acrescentado).

Tenho insistido em que nem toda concepção de atividade científica viabiliza um vínculo duradouro entre as atividades científica e industrial. Pois o excerto acima ilustra particularmente bem como é a atuação em favor de uma concepção que efetivamente o faz. Thomson se distinguia de seus contemporâneos, por mais briIhantes que fossem como químicos, exatamente por sua forma de atuação. Nesse particular, não havia diferença entre ele e Liebig. Sendo 30 anos mais velho que Liebig, Thomson o precedeu na oferta de cursos com aula prática de química. Entre 1807 e 1811, por exemplo, seu curso de química com aulas práticas era o único disponível em Edimburgo (Morrell, 1972: 12-13).

Mas, cada qual ao seu próprio modo, ambos fizeram com que chegasse à Inglaterra o estilo peculiar de trabalho que compartilhavam e a concepção radicalmente nova de atividade científica inerente a esse estilo. Thomson fez essa concepção chegar

16. Carta de Thomson a Robert James, professor de história natural na Universidade de Edimburgo, em 9 de setembro de 1817 , citado por Morrell (1972: 2). 
17. Talvez não seja ocioso esclarecer que, em seu "estado natural", o cloro é um gás.

18. Margaret Jacob (1997) mostra que, nos séculos XVIII e XIX, um industrial inglês tinha um domínio do conhecimento científico de sua época muito maior que um industrial francês. à Inglaterra através de Graham, que, a propósito, não teria saído da sua Escócia se os próprios reformadores educacionais escoceses não tivessem fundado, a duras penas, na Inglaterra, a University College London. Von Liebig, por sua vez, a fez chegar através de Hofmann, que, a propósito, não teria saído de sua Alemanha - para onde, aliás, retornou quando deixou de encontrar na Inglaterra as condições de trabalho que o levaram a emigrar - se as seguidas visitas de seu mentor à Inglaterra não tivessem resultado na criação, nesse país, ainda que a duríssimas penas, do Royal College of Chemistry (Roberts, 1976). Por aí se vê o quanto a "cultura científica inglesa", não obstante sua incomparável exuberância, foi irrelevante para o advento da atividade científica tal como veio a se afigurar e ser efetivamente exercida na Inglaterra da segunda metade do século XIX!

Embora Thomson tenha precedido Liebig, este último foi muito mais bem-sucedido em institucionalizar essa nova concepção de atividade científica porque sua área de atuação era a então nascente química orgânica, sem a qual todo um novo ramo da atividade industrial - a fabricação de produtos sintéticos --, com seu impacto avassalador sobre a agricultura e a indústria têxtil em um primeiro momento, e a indústria de medicamentos, alimentos e cosméticos em um segundo, simplesmente não poderia existir. Thomson, nesse particular, estava em desvantagem, uma vez que não era, e nem teria como ser, versado nessa nova disciplina. Sua área de atuação era a análise quantitativa de minerais, atividade que, embora sem vínculo com a indústria do alcatrão mineral - que só veio a existir quatro anos após sua morte -, era estreitamente vinculada à fabricação em escala industrial de produtos inorgânicos como o cloro em estado líquido (ou mesmo em pó) ${ }^{17}$, o amoníaco, o alúmen de potássio (mais conhecido como "pedra hume") e o pigmento ultramar. Walter Crum, John Tennant, Alexander Harvey, Hugh Colquhoun e John Tennent são alguns dos industriais que se destacaram na fabricação de produtos dessa natureza na Glasgow das décadas de 1820 a 1860 (Morrell, 1972: 21-22). Todos eles iniciaram a trajetória de industrial aprendendo química nos laboratórios abertos por Thomson (Morrell, 1972: 22). Não obstante, Graham desfruta hoje de um reconhecimento maior que Thomson. Suas realizações científicas são, muito mais que as de Thomson, conhecidas dos bons historiadores da química. Mas não foram essas realizações, como da mesma forma não foram as de Liebig, nem as de Hofmann, que puseram a atividade científica em contato com a atividade industrial no século XIX. Nem tampouco o foi, como sugerido por alguns historiadores da ciência, o extraordinário conhecimento de física e matemática que era característico de um fabricante inglês desde o remoto início do século XVIII ${ }^{18}$. O que colocou as referidas atividades em contato foi, conforme já dito pelo velho Weber, o uso do laboratório como parte essencial da formação em química. Mas, por quê? O que de tão importante se aprendia nos laboratórios a ponto de fazer de quem neles se 
formava a base para o êxito de uma indústria química? O que se aprendia nas aulas de laboratório que fazia, do que foi efetivamente aprendido, o ponto de contato entre a indústria e a ciência?

Em um pronunciamento muito irreverente, feito em 1910, um químico inglês que assinava I. Singer dá a entender que nada de muito importante acontecia. No apagar das luzes do século XIX e início do século XX todos concordavam que a Inglaterra estava carente de bons químicos fabris. Singer admitia isto, mas, remando contra a corrente, argumentava que essa carência era um problema que resultava da falta de indústrias precisando de químicos, e não de escolas preparadas para formá-los. Afinal, dizia ele com indisfarçável ironia,

de uma nação que já produziu homens como Boyle, Dalton, Davey, Graham, Priestley, Kelvin, Faraday, Darwin, Tyndall, Huxley, Babbage, Arkwright, Stephenson, Watt, Bessemer, Cartwright, Ramsay, Dewar, Perkin e Meldola não é de se esperar alguma dificuldade para dispor de homens capazes de aprender a sulfonar o fenol ou diazotizar uma amina (Singer, 1910, destaque acrescentado) ${ }^{19}$.

Esse comentário cáustico sugere que, para além de operações rotineiras, embora difíceis, como "sulfonar o fenol" e "diazotizar uma amina" nada há de relevante para ser aprendido nos laboratórios. Por mais caricatural e lacunar que esse comentário possa parecer, ele é, entretanto, útil, porque nos faz lembrar que até mais ou menos o ano de 1870 a indústria química inglesa era pródiga em dispor de homens capazes de "sulfonar o fenol" e "diazotizar uma amina"20, mas, a partir da década de 1870, esse quadro começou a mudar. Coincidência ou não, homens capazes de submeter os mais variados compostos orgânicos, como o fenol e várias aminas, extraídos do alcatrão mineral a operações as mais variadas - como a sulfonação, nitração e diazotização - começaram a escassear na Inglaterra depois que Hofmann deixou o Royal College of Chemistry - ele o fez em 1865 para assumir a direção de um laboratório em Berlim. Perkin, diga-se de passagem, seu já citado ex-aluno que se tornou célebre por fundar a primeira indústria de exploração de alcatrão mineral no mundo, também deixou a Inglaterra, atraído pela indústria química alemã.

Mas a irreverência de I. Singer é útil por uma razão adicional e mais importante: ela chama atenção para duas ordens de expectativa em relação à atividade científica que não estão necessariamente relacionadas, embora Singer supusesse que estivessem. A primeira é a das grandes realizações científicas, tais como as legadas por homens como os que ele próprio se deu ao trabalho de listar. Nesse plano, a Inglaterra sempre permaneceu muito bem servida. Para me limitar ao exemplo da

19. Eu próprio enfatizei os nomes de Ramsay, Dewar, Perkin e Meldola, aos quais ainda retorno. Esclareço, ademais, que "diazotizar" é uma palavra da língua portuguesa que significa adicionar a uma substância dois átomos de nitrogênio. Quanto a "sulfonar", é meramente o meio que encontrei para traduzir "sulphonate". Mas existe a palavra "sulfonação", que é um tipo especial de reação química que não ouso tentar descrever aqui.

20. A começar por ninguém menos que William Perkin, já apresentado ao leitor, a quem se credita o feito de ter obtido pela primeira vez um corante sintético, conhecido, aliás, como a "malva de Perkin". Não sei dizer se Perkin aprendeu a "sulfonar o fenol", mas estou certo de que aprendeu como ninguém, a "nitracionar o fenol", pois é exatamente através da "nitração" desse composto orgânico que se obtém a "malva de Perkin". 
21. Henry Roscoe reproduz esse trecho escrito por Hofmann ao fazer menção ao fato de o próprio Hofmann ter pesquisado se há benzeno no alcatrão mineral, mas infelizmente não cita a fonte.
University College London, nesta, Graham foi sucedido por Williamson - que, a propósito, foi aluno de Liebig em Giessen -, um reconhecido monumento da química de sua época, que, por sua vez, foi sucedido, em 1877, por William Ramsay (18521916), Prêmio Nobel de química em 1904, a quem devemos a descoberta dos gases nobres (Collie, 1927: 26). Ocorre, entretanto, que grandes realizações não pressupõem, necessariamente, a formação para o trabalho sistemático dos laboratórios. A segunda ordem de expectativas diz respeito a esse trabalho. Este, conforme acabamos de ver, conecta a atividade científica à industrial na medida em que conduz ao aprendizado das operações químicas por meio das quais um composto orgânico se transforma em um produto sintético. Mas não é só por esse meio que ele faz essa conexão. Ele o faz, também, por um meio muito mais importante: a contínua exposição do químico a problemas miúdos que só podem ser resolvidos por meio da investigação empírica, no exato sentido em que hoje entendemos essa expressão. Para dar ao leitor uma ideia do que estou chamando de "problema miúdo" ofereço o seguinte exemplo:

Frequentemente se afirma nos mémoires e nos livros-textos que o alcatrão mineral contém benzeno. Eu, entretanto, desconheço qualquer pesquisa na qual esse problema tenha sido investigado (Roscoe, 1915: 119) 21.

Coincidentemente isso foi dito por Hofmann, em pessoa, mas poderia ter sido dito por qualquer químico que tivesse se formado no Royal College of Chemistry, onde Hofmann imprimiu sua marca. O caso de Raphael Meldola (1849-1915) é exemplar. Em artigo escrito em 1886 (Meldola, 1915) ele mostrou como esse compromisso com a investigação empírica sistemática, hoje tão trivial, mas nada trivial na época, embora já o fosse para Hofmann na década de 1840, se relaciona com a atividade industrial. Da mesma forma que Hofmann fez da presença do benzeno no alcatrão mineral um problema de investigação empírica, Meldola o fez das propriedades de um composto orgânico chamado quinolina, do qual se poderia derivar um outro composto, a flavanilina. O ponto a ser destacado é que essa investigação não tinha, em princípio, qualquer conexão com interesses industriais, mas, ao prosseguir, veio a ter, porque acabou por conduzir ao conhecimento, esse sim de interesse industrial, que um terceiro composto orgânico, a crisanilina, que pode ser usada na fabricação de tinturas, também era derivada da quinolina (Meldola, 1915: 129). Anteriormente, indaguei o que de tão importante se aprendia nas aulas de laboratório a ponto de fazer do aprendizado assim obtido a chave para o funcionamento de uma indústria química. Posso agora oferecer a resposta: aprendia-se a pesquisar, essa atividade que hoje nos é absolutamente familiar, mas soaria estranha para muitas das figuras exponenciais citadas naquela extensa lista de I. Singer. Com efeito, se algum químico dos nossos dias pudesse viajar no tem- 
po e se apresentar aos homens citados naquela lista como um "pesquisador", por muitos ele não se faria entender. É certo que todas as figuras exponenciais citadas por Singer pesquisavam, mas não no sentido que hoje entendemos esse termo. Mas devo me concentrar naqueles que compartilham o sentido hodierno desse termo: Meldola, cujo estilo de trabalho espelhava o estilo que havia sido imprimido no Royal College of Chemistry, sua alma mater, por Hofmann e James Dewar (1842-1932), que agora apresento ao leitor, pelas razões que exponho a seguir.

Em discurso proferido na sessão plenária de abertura do Congresso da British Association for the Advancement of Science, realizado em Belfast, em 1902, Dewar exprimiu com rara felicidade o modo como hoje entendemos o que seja "conduzir uma investigação científica" ou, simplesmente, "pesquisar", ao afirmar:

\begin{abstract}
Há um grande número de químicos formados, mesmo por nossas universidades, que não teriam como trabalhar em uma indústria como a Bayer \& Co. Eles conhecem muitas fórmulas, sabem recitar teorias, conhecem os livros-textos de cor; mas coloque-os para resolver um problema novo, que acabou de surgir no laboratório, e descobrirá que tudo o que aprenderam é letra morta. 0 aprendizado não se tornou, para eles, uma parte vital de seus equipamentos mentais e, em decorrência disso, eles ficam paralisados ao primeiro sinal do inesperado (Dewar, 1915: 225, destaque acrescentado).
\end{abstract}

Eis assim, em brevíssimas palavras, de onde surgiu a concepção hoje corrente de investigação científica ou, simplesmente, "pesquisa": da demanda por resolver "novos problemas" que tendem a surgir nos laboratórios. Problemas, por assim dizer, "miúdos", como, por exemplo, investigar se há mesmo benzeno no alcatrão mineral. A Inglaterra era a terra de Newton, Boyle, Faraday e mais uma ou duas dezenas de figuras científicas exponenciais, incluindo o próprio Dewar, mas, em pleno final do século XIX, não era a terra em que estava aberta, a centenas de cientistas em formação, a oportunidade para se defrontar continuamente com "problemas novos", surgidos do trabalho árido, insosso e miúdo da rotina dos laboratórios. A chegada de uma figura como Hofmann - pelas mãos de Liebig -, em 1845, significou a mais plena abertura dessa oportunidade, e a saída dessa mesma figura, em 1865, significou, em poucos anos, o declínio dessa oportunidade. Das consequências desse declínio me ocupo na próxima seção. Por ora, devo dizer que tanto para Liebig, quanto para Hofmann, o interesse por problemas intrinsecamente relacionados com a química tinha prioridade sobre os interesses industriais. Um químico poderia - e deveria - ocupar-se de perguntas relativas a como utilizar o solo da forma mais racional possível, como produzir, em grande escala, fertilizantes eficientes, como criar estampas que não descolorem, como produzir drogas e corantes a partir de 
compostos orgânicos, como, em resumo, produzir em larga escala aquilo que, sem a ajuda da química, não poderia ser produzido de modo algum ou só o poderia em pequena escala. Mas essas perguntas teriam que estar sempre subordinadas a perguntas intrinsecamente relacionadas com a produção do conhecimento de química.

A ciência em cujo nome Liebig e Hofmann atuavam era a que buscava oferecer, em primeiro lugar, solução para os novos problemas que surgem continuamente do trabalho rotineiro dos laboratórios, para, depois, ocupar-se dos problemas relacionados aos interesses industriais. Era assim, acreditavam eles, que a ciência poderia servir à indústria e dela se servir em contrapartida. Era assim que se fazia na Alemanha da segunda metade do século XIX, a acreditar nos discursos dos mais eminentes químicos ingleses que se pronunciaram sobre a ascensão vertiginosa da indústria química alemã nesse período. Von Hofmann permaneceu na direção do Royal College of Chemistry enquanto Ihe foi possível priorizar a pesquisa orientada para o avanço do conhecimento de química. Quando não o foi mais, por razões que permanecem sendo objeto de controvérsia, ele perdeu o interesse em se manter na Inglaterra. Retornou para a sua Alemanha, dessa vez para Berlim, onde pôde continuar a pesquisar, na mais contemporânea acepção da palavra.

Henry Armstrong, um destacado ex-aluno que se referia a Hofmann como o "nosso compatriota adotado", manifestou-se a respeito lembrando que foram os alunos de Hofmann que estabeleceram a indústria de alcatrão mineral na Inglaterra; que Hofmann "fez o melhor que pôde para erguer a árvore inglesa da indústria química e, por algum tempo, essa se ergueu em paz", mas, "o círculo dentro do qual as condições favoráveis prevaleceram foi desgraçadamente muito estreito" e, como resultado, "as raízes" dessa árvore "foram arrancadas" e "a árvore parou de florescer". Ele conclui dizendo que os ingleses negaram a Hofmann a oportunidade

\footnotetext{
que ele avidamente aproveitou quando Ihe foi oferecida por seus patrícios: entre eles, encontrou Boden und Nahrung [solo e alimentação], pois eles haviam sido apropriadamente talhados por suas universidades e estavam preparados para aceitar seu conseIho de aplicar a teoria à prática (Armstrong, 1986: 730).
}

Em outras palavras, Hofmann pretendia se dedicar à pesquisa científica, no sentido que contemporaneamente entendemos essa expressão, e enxergou na Alemanha o lugar ideal para fazê-lo. 
Anteriormente comparei os desempenhos industriais inglês e alemão no final do século XIX pelos respectivos números de patentes registradas. Prometi para mais tarde indicadores mais eloquentes da situação desoladora a que a indústria química inglesa foi conduzida. É chegado o momento de mostrar esses indicadores, nem todos traduzíveis em números; é chegado o momento de mostrar, em outras palavras, o que acontece quando uma atividade industrial que nasce umbilicalmente vinculada à atividade científica se desvincula dessa atividade. Inicio com um tiro de canhão, aliás, dois, um desferido por Meldola, outro por Dewar, ambos já familiares ao leitor. Retorno, primeiro, ao ano de 1862, mais precisamente, à ocasião em que ainda era possível alardear, como Hofmann o fizera - ao relatar o desempenho da Inglaterra na Grande Exposição daquele ano -, a "incontestável superioridade" da indústria química inglesa sobre a de qualquer outro país do mundo. Pois, passados apenas 24 anos, em 1886, eis o que Meldola tinha a relatar sobre a situação a que havia chegado à indústria química inglesa:

O estado atual das coisas é que nossos concorrentes estão em
condições de importar nossas matérias-primas, fabricar com elas
os corantes e nos venderem de volta, de modo a competirem exi-
tosamente conosco em nosso próprio mercado e desvalorizar nos-
sos corantes no mercado externo (Meldola, 1886) ${ }^{22}$.

Os corantes sintéticos podiam, na época, ser feitos a partir da anilina e da azilarina, sendo que a azilarina é uma base muito melhor. Havia ainda o índigo, mas não disponho de informações sobre ele. Era uma espécie de "segunda geração" de corantes, se é que posso assim me expressar. Pois, na virada do século, os fabricantes-membros da Associação Britânica de Estampadores praticamente já não compravam mais corantes fabricados na Inglaterra. Eles importavam 98,35\% dos corantes feitos à base de alizarina e $78 \%$ dos corantes feitos à base de anilina! Esses dados foram apresentados pelo químico Arthur G. Green em um discurso proferido, em 1901, perante a referida associação, a British Cotton and Wool Dyers Association (Green, 1915: 196). Não há informação sobre a proporção de corantes importados da Alemanha. Mas presumo que fosse elevada, uma vez que, de 1890 a 1899, enquanto as exportações da indústria alemã subiram de $£ 594$ mil para $€$ 708,8 mil, as da indústria inglesa caíram de $£ 530$ mil para $\mathrm{f}$ 366,5 mil (Green, 1915: 196).

No já citado discurso presidencial, proferido por James Dewar no Congresso da British Association for the Advancement of Science, em 1902, há uma passagem que resume esplendidamente tudo isto. Após descrever brevemente a prosperidade já ostentada desde pelo menos 1875 pela firma Friedrich, Bayer \& Co., indústria
22. Republicado por Gardner (1915: 124). 
química alemã que posteriormente viria a ser a planetariamente conhecida Bayer, Dewar pontificou:

\begin{abstract}
Devo repetir que as descobertas fundamentais a partir das quais esta gigantesca indústria alemã foi construída foram feitas neste país [a Inglaterra], e os mesmos que fizeram essas descobertas são os que até certo ponto estabeleceram, neste mesmo país, os meios para que os produtos delas resultantes pudessem ser fabricados em escala industrial. Mas, apesar da abundância da matéria prima e do seu baixo custo neste país [...], esses homens não fundaram escola alguma, e praticamente não tiveram sucessores. As cores que eles [os ingleses] criaram foram expulsas do campo por cores mais novas e melhores, feitas a partir do material produzido por eles, através do desenvolvimento das ideias deles, mas essas cores melhoradas foram feitas na Alemanha, e não na Inglaterra (Dewar, 1915: 224, destaque acrescentado).
\end{abstract}

Dewar não esclarece quem são esses homens que não fundaram escola alguma nem tiveram sucessores, mas a alusão a eles remete ao fato de o trabalho de laboratório de Hofmann não ter tido continuidade na Inglaterra após seu retorno à Alemanha. Após a saída de Hofmann, o Royal College of Chemistry só existiu enquanto tal por mais sete anos. Em 1872 passou a ser meramente o "Departamento de Química" da Royal School of Mines. Os efeitos dessa descontinuidade são visíveis em um quadro comparativo, ainda que precário, sobre a disponibilidade de químicos devidamente formados e treinados na Inglaterra e na Alemanha da virada do século XIX para o século XX. De 1886 a 1901, o número de químicos empregados em indústrias alemãs subiu de 1.700 para 4.500. Não há dados sobre a evolução do emprego de químicos nas indústrias inglesas, mas estima-se que em 1901 esse número estava entre 1.500 e 2.000 (Dewar, 1915: 222-226).Dewar deplora esta situação nos seguintes termos:

Não podemos dispor no Reino Unido, não obstante a imensa variedade de indústrias químicas em que fomos uma vez preeminentes, de mais do que um terço do staff profissional empregado na Alemanha (Dewar, 1915: 222-223, destaque acrescentado).

O quadro se mostra ainda mais eloquente quando se compara a qualificação dos químicos dos dois países no período em questão:

Na mais otimista das estimativas, e ignorando o fato de que o treinamento das universidades alemãs é muito mais rigoroso, uma vez que conferem graus aos seus alunos pelo trabalho que estes fazem nos laboratórios, e não pelas respostas que escrevem em um pedaço de papel, temos apenas 31\% de químicos treinados 
sistematicamente, contra $84 \%$ em fábricas alemãs. [...] Esses números, que, eu suspeito, são bastante favoráveis ao lado inglês, apontam inequivocamente para a prevalência, em nosso país, da antiquada adesão à "regra do polegar" (rule of thumb), que está na raiz do atraso que temos que deplorar (Dewar, 1915: 222-223, destaque acrescentado).

Mais uma vez, o contraste com os tempos de Hofmann não poderia ser maior. Afirmar a prevalência da "regra do polegar" é, ao fim e ao cabo, afirmar que o vínculo entre a química e a indústria química se desfez. Na verdade, nenhuma ciência pode prescindir de um farto repertório de "regras do polegar", isto é, regras gerais, baseadas na experiência, para a solução de problemas com os quais qualquer cientista está a qualquer momento sujeito a se defrontar. A "sulfonação de um fenol", por exemplo, não pode prescindir de uma dose considerável de "regras do polegar", mesmo porque, dentre os riscos inerentes a essa operação, está incluído o de explosão. Somente um rico repertório de "regras do polegar" pode ajudar quando se trata de evitar a explosão de um laboratório durante uma "sulfonação". Mas, do fato de ser inevitável o recurso a "regras do polegar" não se segue que a adesão a elas possa prevalecer, como ocorre no caso do mecânico de automóvel, que nada entende de mecânica propriamente, ou do eletricista que instala um chuveiro, que nada entende de eletricidade propriamente. Quando o uso dessas regras chega a prevalecer, estamos de volta ao tempo da indústria química sem química, a que fiz referência no primeiro parágrafo do presente artigo. A experiência inglesa mostrou que esse é um tempo que não fica necessariamente confinado a um passado. Pelo menos na Inglaterra, o tempo da indústria química sem química pôde ser exatamente o mesmo tempo em que um químico inglês, o anteriormente mencionado William Ramsay, veio a ser laureado com o Prêmio Nobel de química.

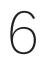

Quando, no alvorecer do século XX, Weber mencionou incidentalmente a conexão da indústria com o "trabalho sistemático dos laboratórios", ele involuntariamente chamou a atenção para o fato de que esse trabalho estabeleceu uma concepção de atividade científica até então desconhecida. Essa nova concepção, ouso afirmar, conduziu ao vínculo duradouro, característico do nosso tempo, entre a indústria e a ciência moderna. Da mesma forma que esse vínculo se faz, a experiência inglesa mostrou que ele também pode se desfazer. Neste artigo procurei dizer alguma coisa a respeito do modo como esse vínculo se fez, se desfez e, posteriormente, se refez em outro lugar. Ele pode prescindir de grandes descobertas científicas, de inventos espetaculares, de uma cultura científica exuberante, mas não da existência de um 
ambiente institucional em que cientistas possam se formar em grande número e em que a investigação empírica possa ser conduzida de forma sistemática. Em 1837, um químico alemão - um certo Justus Liebig - visitou a Inglaterra e se mostrou chocado ao perceber o quanto o ambiente institucional para a atividade científica, tal como ele a concebia, era rarefeito naquele país. Cerca de seis décadas mais tarde são os próprios ingleses, incluindo figuras exponenciais como Meldola e Dewar, que se mostram chocados por essa mesma razão. Nesse intervalo, o ambiente inglês tornou-se mais apropriado para o trabalho sistemático dos laboratórios, mas, ainda assim, não reteve aqueles que foram os principais responsáveis pela mudança nem formou quem pudesse levá-la adiante. Ninguém exprimiu melhor o resultado desse insucesso do que James Dewar, ao mencionar, conforme vimos, que as cores que em um passado nem tão remoto tinham sido criadas pelos ingleses, a partir da matéria prima produzida pelos ingleses, e através do desenvolvimento das ideias dos ingleses, foram "expulsas do campo" e substituídas por cores mais novas e melhores, agora feitas, ainda em boa medida, por químicos ingleses, mas na Alemanha.

\section{Referências}

ASHTON, Rosemary. Victorian Bloomsbury. New Haven (CT); Londres: Yale University Press, 2012.

BERNAL, John Desmond. Science and industry in the nineteenth century. London: Routledge, 2011 [1953].

1971 [1954].

CARRIÈRE, J. (Ed.). Berzelius und Liebig: Ihre Briefe von 1831-1845 (Munich e Leipzig). In: FRUTON, Joseph S. The Liebig Research Group: a reappraisal. Proceedings of the American Philosophical Society, v. 132, n. 1, p. 1-66, 1988.

COLLIE, John Norman. A century of chemistry at University College, sixth of a series of centenary adresses. In: Centenary adresses bound together in one volume. London: University of London Press, 1927.

DEWAR, J. Applied chemistry, english and foreign. Abstract from Presidential Address. In: GARDNER, Walter M. The British coal-tar industry, its origin, development, and decline. London: Wiliams and Norgate, 1915 [1902].

FRUTON, Joseph S. The Liebig Research Group: a reappraisal. Proceedings of the American Philosophical Society, v. 132, n. 1, p. 1-66, 1988. 
GARDNER, Walter M. The British coal-tar industry, its origin, development, and decline. London: Wiliams and Norgate, 1915.

GREEN, Arthur G. The relative progress of the coal-tar colour industry in England and German during the past fifteen years. In: GARDNER, Walter M. The British coal-tar industry, its origin, development, and decline. London: Wiliams and Norgate, 1915 [1901].

HALL, A. Rupert. What did the Industrial Revolution in Britain owe to Science? In: MCKENDRICK, Neil (Ed.). Historical perspectives: studies in English Thought and Society in honour of J. H. Plumb, p. 129-151. London: Europa Publications, 1974.

JACOB, Margaret. Scientific culture and the making of industrial West. New York: Oxford University Press, 1997.

JACOB, Margaret; STUART, Larry. Practical matter: Newton's science in the service of industry and Empire, 1687-1851. Cambridge (MA): Harvard University Press, 2004.

MAAR, Juergen Heinrich. Justus von Liebig. 1803-1873. Química Nova, v. 29, n. 5, p. 1129-1137, 2006.

MCKENDRIX, Neil. The role of science in the industrial revolution. In: TEICH, Mikulas; YOUNG, Robert (Orgs.). Changing perspectives in the history of science, p. 274319. London: Heinemann, 1973.

MELDOLA, Raphael. The scientific development of the coal-tar industry. In: GARDNER, Walter M. The British coal-tar industry, its origin, development, and decline, $\mathrm{p}$. 121-140. London: Wiliams and Norgate, 1915 [1886].

MOKYR, Joel. The European enlightment, the Industrial Revolution, and modern economic growth. Conferência proferida em 27 Mar. 2007, Max Weber Lecture Series, European University. Disponível em: <https://sites.northwestern.edu/jmokyr/ files/2016/06/The-European-Enlightenment-the-Industrial-Revolution-and-Modern-Economic-Growth-2007-2j6gh1e.pdf>.

. The intelectual origins of modern economic growth. Journal of Economic History, v. 65, n. 2, p. 285-351, 2005.

MORRELL, John Bowes. The chemist breeders: the research schools of Liebig and Thomas Thomson. Ambix, v. 19, p. 1-46, 1972.

MUSSON, Albert E.; ROBINSON, Eric. Science and technology in the Industrial Revolution. Manchester (UK): Manchester University Press, 1969. 
PLAYFAIR, Lyon. Personal reminiscences of Hofmann and of the conditions which led to the establishment of the Royal College of Chemistry and the appointment of its professor. Journal of the Chemical Society, Transactions, v. LXIX, Parte I, p. 575579, 1896.

ROBERTS, Gerrylynn K. The establishment of the Royal College of Chemistry: an investigation of the social context of early-victorian chemistry. Historical Studies in the Physical Sciences, v. 7, p. 437-485, 1976.

ROSCOE, Henry. Recent progress in the coal-tar industry, discourse delivered at the Royal Institute, 1886. In: GARDNER, Walter M. The British coal-tar industry, its origin, development, and decline. London: Wiliams and Norgate, 1915.

SINGER, I. The coal-tar colour industry of England: causes of its progresses and retardation. In: GARDNER, Walter M. The British coal-tar industry, its origin, development, and decline, p. 284. London: Wiliams and Norgate, 1915 [1910].

STEWART, Larry. The selling of Newton: science and technology in early eighteenth-century England. Journal of British Studies, v. 25, n. 2, p. 178-192, 1986.

TILDE, William A. The supply of chemicals to Britain and her dependences. In: GARDNER, Walter M. The British coal-tar industry, its origin, development, and decline. London: Wiliams and Norgate, 1915 [1914].

WEBER, Max. General economic history. London: Transaction Publishers, 2003 [1923]. 